\title{
PENGARUH KNOWLEDGE MANAGEMENT TERHADAP PENINGKATAN KINERJA UMKM DENGAN KOMPETENSI SEBAGAI VARIABEL MODERASI
}

\author{
Wahid Wachyu Adi Winarto \\ Institut Agama Islam Negeri Pekalongan
}

Email korespondensi: wahidwachyuadi@iainpekalongan.ac.id

Received: 21 July 2020 Reviewed: 25 Aug 2020 Accepted: 12 Oct $2020 \quad$ Published:30 Oct 2020

\begin{abstract}
This study aims to analyze the effect of knowledge management consisting of knowledge implementing, knowledge creating, and knowledge sharing on the improvement of the performance of Small Medium Enterprises (SMEs). In addition, it is also to determine whether competence can moderate the knowledge management variable on the performance of SMEs. This study used data from 57 SMEs in Kabupaten Pemalang as sample. Data were analyzed using multiple linear regression analysis, $t$ test and $F$ test and for the moderation test using the MRA (Moderated Regression Analysis). From the results of the analysis, it was obtained that partial knowledge implementation, knowledge creating, and knowledge sharing have significant positive effects on the performance of SMEs. Simultaneously, knowledge management has a positive effect on the performance of SMEs. The result of moderation test using MRA shows that competence cannot moderate the effect of knowledge implementing, knowledge creating dan knowledge sharing on the performance of SMEs.
\end{abstract}

Keywords: Knowledge Management, Knowledge Implementing, Knowledge Creation, Knowledge Sharing, Performance, Competency

\begin{abstract}
ABSTRAK
Penelitian ini bertujuan untuk menganalisis pengaruh knowledge management yang terdiri dari knowledge implementing, knowledge creating, and knowledge sharing terhadap peningkatan kinerja UMKM. Selain itu juga untuk mengetahui apakah kompetensi dapat memoderasi variabel knowledge management terhadap kinerja UMKM. Sampel dalam penelitian ini adalah 57 UMKM di Kabupaten Pemalang. Data di analisis menggunakan analisis regresi linier berganda, $t$ test, $F$ test dan untuk tes moderasi dgunakan Moderated Regression Analysis (MRA). Dari hasil analisis diperoleh hasil secara parsial secara parsial knowledge implementing, knowledge creating, and knowledge sharing memiliki pengaruh positif signifikan terhadap peningkatan kinerja UMKM. Secara simultan, knowledge management juga memiliki pengaruh positif terhadap UMKM. Hasil test moderasi menggunakan MRA menunjukkan bahwa kompetensi tidak mampu memoderasi hubungan antara knowledge implementing, knowledge creating dan knowledge sharing terhadap kinerja UMKM.
\end{abstract}

Kata kunci: Knowledge Management, Knowledge Implementing, Knowledge Creation, Knowledge Sharing, Kinerja, Kompetensi 


\section{A. PENDAHULUAN}

Peningkatan pertumbuhan UMKM sangat membantu pertumbuhan ekonomi negara. Hal ini dikarenakan UMKM merupakan salah satu faktor penentu keberhasilan perekonomian (Bank Indonesia dan LPPI, 2015). Pertumbuhan perekonomian tahun 2019 sebesar 5\%, peran pemerintah dibutuhkan untuk meningkatkan perekonomian dengan memberikan dukungan kepada pengusaha UMKM. Keberadaan UMKM tersebar di seluruh tanah air Indonesia menguasai sekitar 99\% aktivitas bisnis di Indonesia, dengan lebih dari 98\% berstatus usaha mikro (Kompas.com). Perkembangan UMKM di Jawa Tengah mengalami perkembangan dari tahun ke tahun dengan tingkat pertumbuhan 7.52\% tahun 2018 dari tahun 2017, dengan serapan tenaga kerja 1.043.320 pekerja (dinkop-umkm.jatengprov.go.id). Perkembangan tersebut dapat menyerap tenaga kerja dan menurunkan tingkat pengangguran di Jawa Tengah.

Kegiatan usaha mikro, kecil, dan menengah di Indonesia pada tahun 2020 mengalami terpaan dari dampak lesunya perekonomian nasional yang pada kuartal ke II tahun 2020 Indonesia ke arah resesi dengan pertumbuhan minus 5.32\% (www.money.kompas.com). Lesunya perekonomian diakibatkan karenakan dampak dari adanya pandemi Covid-19. Banyak UMKM yang bangkrut dan menurun pendapatannya. Sedikitnya 39,9\% usaha kecil menengah (UKM) memutuskan mengurangi stok barang selama pembatasan sosial berskala besar (PSBB) akibat Covid-19. Sementara itu, 16,1\% UKM memilih mengurangi karyawan akibat toko fisik ditutup (www.ekonomi.bisnis.com).

Pembangunan daerah diarahkan untuk pengembangan kegiatan ekonomi yang dapat memberikan kesejahteraan kepada masyarakat. Salah satunya dengan meningkatkan kinerja UMKM supaya tahan terhadap krisis dan perekonomian yang kurang mendukung. Perkembangan UMKM membawa kompetisi yang semakin ketat, akibatnya UMKM yang tidak mampu berkompetisi akan tergusur dari persaingan usaha. Adapun upaya yang dapat dilakukan untuk dapat menjadikan UMKM agar lebih bisa berkompetisi, mandiri, dan memberikan kontribusi pada perekonomian daerah adalah melalui peningkatan knowledge pemilik UMKM melalui berbagai cara dan kebijakan yang ditempuh oleh pemerintah daerah.

Banyak sekali kendala saat ini yang harus dihadapi UMKM diantaranya kekurangan modal usaha, kekurangan akses terhadap teknologi yang tidak sebanding dengan perkembangan teknologi. Selain itu UMKM memiliki keterbatasan dalam pemasaran produk, kurangnya kualitas sumber daya manusia. Terlebih lagi pengelolaan manajemen UMKM yang masih bersifat tradisional belum ke arah modern. 
Pemerintah dalam upaya pemberdayaan UMKM harusnya bukan hanya dalam masalah permodalan saja melainkan harus menempatkan UMKM sebagai pelaku bisnis yang harus berkembang dari waktu ke waktu (Sudiarta, Kirya, \& Cipta, 2014). Adapun peran pemerintah dapat memposisikan UMKM sebagai sebuah organisasi yang terus belajar sehingga selalu dapat mengembangkan inovasi yang akan memiliki kompetitif yang tinggi. UMKM membutuhkan perkembangan teknologi dalam menghadapi tantangan di era 4.0 sekarang ini. Salah satu peningkatan teknologi di UMKM adalah dengan perkembangan fintech di UMKM sehingga dapat meningkatkan inklusi keuangan dan literasi keuangan bagi UMKM (Wachyu \& Winarto, 2020). Hal tersebut ternyata juga masih kurang membantu dalam peningkatan usaha UMKM tanpa diikuti oleh kemampuan pengetahuan dalam pengelolaan manajemen yang baik.

Pengelolaan pengetahuan terhadap manajemen sering kita sebut dengan istilah knowledge management. Hal ini merupakan strategi yang diarahkan kepada pemilik organisasi tentang pengetahun dalam manajemen sebuah organisasi supaya diharapkan dapat meningkatkan kinerja UMKM yang memiliki kompetensi dan berdaya saing. Namun, beberapa penelitian menunjukkan bahwa knowledge management masih sangat rendah yang dimiliki oleh UMKM (Humaira \& Sagoro, 2018). Berbagai macam faktor diungkapkan diantaranya latar belakang pendidikan, skala usaha, dan umur perusahaan. Selain beberapa penelitian juga mengungkapkan UMKM kurang memahami faktor lingkungan bisnis antara lingkungan bisnis pada persaingan rendah maupun tingkat persaingan tinggi (Lantu, Triady, Utami, \& Ghazali, 2016). Penelitian ini bertujuan untuk mengetahui pengaruh knowledge management terhadap kinerja UMKM di Kabupaten Pemalang baik secara simultan maupun parsial. Selain itu, juga untuk mengetahui besarnya pengaruh kompetensi dalam memoderasi pengaruh knowledge management terhadap kinerja UMKM.

\section{B. TELAAH PUSTAKA}

\section{Kinerja UMKM}

Kinerja berasal dari kata job performance atau actual performance yang berarti prestasi kerja atau prestasi sesungguhnya yang dicapai oleh seseorang. Pengertian kinerja (prestasi kerja) adalah hasil kerja secara kualitas dan kuantitas yang dicapai oleh seorang pegawai dalam melaksanakan fungsinya sesuai dengan tanggung jawab yang diberikan kepadanya. Ragam pengukuran kinerja dalam bisnis salah satunya dapat dibedakan berdasarkan finansial 
dan non finansial (Islami, Kunaifi, dan Gunawan, 2017). Sebagai ukuran untuk mengetahui perkembangan usaha UMKM salah satunya harus diukur kinerja UMKM baik dari segi finansial maupun non finansial.

Indikator kinerja organisasi diukur berdasarkan beberapa ukuran kinerja organisasi yang sering dilakukan oleh beberapa penelitian. Indikator pengukuran dalam penelitian ini merujuk pada penelitian yang dilakukan oleh Saraswati \& Widiartanto (2016). Indikator pertama yaitu financial perspective atau perspektif keuangan ini berkaitan dengan pemasukan dan pengeluaran perusahaan karena perusahaan harus bisa mengelola keuangan dengan baik supaya keuangannya terus stabil. Kedua, customer perspective berkaitan dengan kemampuan untuk mengelola konsumen sebagai pemakai produk sehingga menimbulkan konsumen yang loyal. Ketiga, internal business perspective berkaitan dengan strategi bisnis yang dimiliki oleh pengelola untuk meningkatkan dan mengembangkan usaha. Indikator ke empat adalah innovation and learning perspective berkaitan dengan inovasi dan pembaharuan produk dan berupa kegiatan-kegiatan pembelajaran baik bersifat formal maupun non formal.

Pengukuran kinerja pada dasarnya merupakan faktor kunci guna mengembangkan suatu organisasi secara efektif dan efisien, karena didukung dengan kebijakan atau program yang lebih baik lagi atas sumber daya yang digunakan dalam organisasi. Pengertian pengukuran kinerja melalui pandangan para ahli. Menurut Wahyudi (2002), pengukuran kinerja adalah gambaran sebuah deskripsi sistematis tentang kekuatan dan kelemahan yang terkait dari seseorang atau kelompok. Selain itu, pengukuran kinerja juga diartikan sebagai tindakan pengukuran yang dilakukan terhadap berbagai aktivitas dalam rantai nilai yang ada pada perusahaan. Hasil pengukuran kinerja dan faktor yang mempengaruhinya digunakan sebagai umpan balik yang akan memberikan informasi tentang prestasi pelaksanaan suatu rencana dan titik dimana pengelola usaha memerlukan penyesuaian dan aktivitas perencanaan dan pengendalian.

\section{Pengetahuan Manajemen (Knowledge Management)}

Pengetahuan manajemen melibatkan segala aktivitas yang terkait dengan perolehan, penggunaan, dan berbagi pengetahuan oleh suatu organisasi. Bukti menunjukkan bahwa praktik-praktik ini semakin sering digunakan dan dampaknya pada inovasi dan aspek-aspek lain yaitu kinerja perusahaan yang tidak boleh diabaikan (OECD/Statistics Canada, 2004). Saat ini, pentingya memahami dan mengukur aktivitas knowledge management sehingga organisasi dapat lebih efisien dan pemerintah dapat mengembangkan kebijakan untuk 
mempromosikan manfaat ini. Macam-macam kebutuhan knowledge management yang dibutuhkan untuk UMKM diantaranya :

\section{Knowledge Implementing}

Informasi dan pengetahuan telah mengubah bisnis, organisasi, dan masyarakat secara mendalam. Knowledge implementing menjanjikan konsep dan instrumen yang membantu organisasi untuk menyediakan lingkungan yang mendukung penciptaan pengetahuan, berbagi, dan aplikasi (Maier, 2007). Konsep yang telah mempengaruhi terintegrasikannya ke dalam kerangka kerja yang terdiri dari strategi, organisasi, dan sistem ekonomi untuk membuat desain yang inspiratif.

\section{Knowledge Creation}

Knowledge creation merupakan pengetahuan untuk mengelola aspek dinamis dari proses penciptaan pengetahuan organisasi (Nonaka, 1994). Kegiatan utamanya adalah bahwa pengetahuan organisasi diciptakan melalui dialog berkelanjutan antara pengetahuan yang eksplisit. Dikatakan bahwa sementara pengetahuan baru dikembangkan oleh individu, organisasi harus meletakkan peran penting dalam mengartikulasikan dan memperkuat pengetahuan itu. Kerangka teoritis dikembangkan yang memberikan perspektif analitis pada dimensi konstituen penciptaan pengetahuan.

\section{Knowledge Sharing}

Menyajikan model motivasi knowledge sharing berdasarkan kombinasi teori perilaku terencana dan teori penentuan nasib sendiri, bersama dengan yang mendukung model dan saran untuk masa depan (Gagné, 2009). UMKM diharuskan memiliki knowledge sharing untuk mempelajari perilaku organisasi. Seperti halnya merancang pentingnya manajemen sumber daya manusia (SDM), termasuk staf, desain pekerjaan, kinerja, gaya manajerial, dan pelatihan.

\section{Kompetensi}

Kompetensi SDM yang diperlukan untuk menghadapi tantangan baru dan jenis-jenis organisasi di tempat kerja, dapat diperoleh dari pemahaman terhadap orang-orang yang bekerja dalam organisasi tersebut. Konsep dasar standar kompetensi ditinjau dari etimologi, standar kompetensi terbuka atas dua kosakata yaitu standar dan kompetensi. Menurut Amstrong (1994), kinerja seseorang didasarkan pada pemahaman ilmu pengetahuan, keterampilan, keahlian, dan perilaku yang diperlukan untuk melakukan pekerjaan dengan baik. Beberapa kriteria yang dapat dianalisis dalam kompetensi SDM antara lain: dorongan 
individu, dampak dan analisis, berpikir strategis, berpikir kreatif, ketegasan dalam mengambil keputusan, penilaian secara komersial, tim manajemen dan kepemimpinan, hubungan antar pribadi, kemampuan berkomunikasi, kemampuan untuk beradaptasi dan mengatasi perubahan dan tekanan, kemampuan merencanakan dan mengendalikan proyek.

Analisis kompetensi menggambarkan sifat seseorang dengan cara menilai pengetahuan, keterampilan khusus yang dibutuhkan, pendidikan, pelatihan dan pengalaman. Penelitian yang dilakukan oleh Hussinki at al (2015) menyatakan bahwa pemahaman yang baik tentang bagaimana knowledge harus dikelola untuk organisasi agar dapat tumbuh berkembang. Penelitiannya juga menunjukkan dampak knowledge management sebagai alat manajerial untuk dapat maju dan berkembang dalam organisasi. Knowledge management berpengaruh signifikan terhadap kinerja karyawan Bank Mayapada KCU Mega Mas Manado. Knowledge management merupakan faktor kuat untuk mendorong kinerja karyawan karena karyawan terus dibekali pengetahuan baru tentang pekerjaan yang akan dilakukan maupun pengetahuan umum di luar pekerjaan (Monsow at all 2017).

Berbagai literatur yang lain menunjukkan bahwa UMKM yang memiliki knowledge management mendapatkan manfaat yang baik dan positif sama dengan perusahaan besar yang menerapkan knowledge management. Termasuk di dalamnya perbaikan kompetensi, efisiensi proses, dan prosedur serta perbaikan pembelajaran, peningkatan inovasi, tanggungjawab kepada pelanggan dan berbagi pengetahuan, perbaikan komunikasi, penguatan komitmen organisasi. Dari hal tersebut terbentuklah keunggulan bersaing yang berkelanjutan. Dari hal tersebut maka knowledge management dipandang sebagai strategi yang dapat menciptakan, memperoleh, mentransfer, membawa ke arah penggunaan pengetahuan dalam rangka memperbaiki kinerja organisasi yang memiliki kompetensi dan unggul dalam persaingan.

Berdasarkan penelitian terhadap implementasi knowledge management sampel penelitian 150 perusahaan di Eropa dan Amerika menghasilkan kesimpulan bahwa dengan melakukan dan peningkatan knowledge management dapat meningkatkan kolaborasi, pemindahan pengetahun konsumen dan peningkatan kinerja. Menurut Lienbowitz dalam Saraswati (2016) menjelaskan bahwa dalam penerapan manajemen pengetahuan terdapat tiga proses dasar yaitu knowledge implementing, knowledge creating, dan knowledge sharing sehingga dapat disimpulkan bahwa implementasi knowledge management terdiri atas tiga knowledge tersebut. 


\section{Kerangka Pemikiran Teoritis}

Gambar 1. Kerangka Pemikiran Teoritis

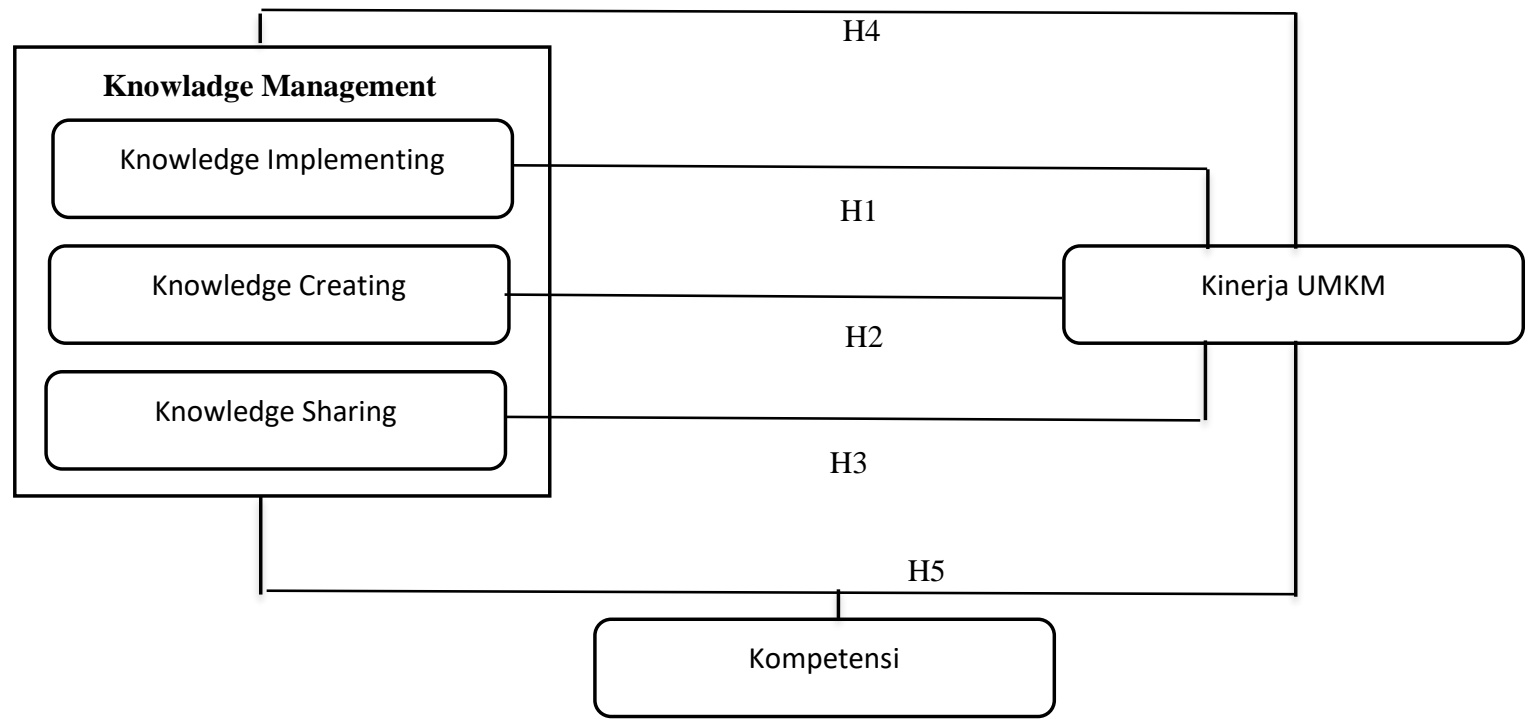

\section{Hipotesis Penelitian}

Dari penjelasan ditelaah pustaka dan kerangka pemikiran maka dapat ditarik hipotesis penelitian sebagai berikut:

$\mathrm{H}_{1}$ : Knowledge implementing berpengaruh terhadap kinerja UMKM

$\mathrm{H}_{2}$ : Knowledge creating berpengaruh terhadap kinerja UMKM

$\mathrm{H}_{3}$ : Knowledge sharing berpengaruh terhadap kinerja UMKM

$\mathrm{H}_{4}$ : Knowledge management berpengaruh simultan terhadap kinerja UMKM

$\mathrm{H}_{5}$ : Kompetensi dapat memoderasi pengaruh knowledge management berpengaruh terhadap kinerja UMKM

\section{METODE PENELITIAN}

Penelitian ini menggunakan metode penelitian explanatory research yang digunakan untuk mengetahui seberapa besar hubungan antar variabel independen yaitu knowledge management. Indikator pengukuran variabel knowledge management terdiri dari knowledge implementing, knowledge creating, knowledge sharing, dan variabel dependen adalah peningkatan kinerja serta variabel moderasi adalah kompetensi.

Populasi dalam penelitian adalah organisasi bisnis mikro kecil dan menengah atau UMKM di berbagai bidang industri, perikanan, dan pertanian di wilayah kabupaten Pemalang. Kuesioner yang disebar sebanyak 100 kuesioner dengan kuesioner berupa pertanyaan dibagikan kepada pelaku UMKM. Dari 100 kuesioner yang dibagikan ada 43 
kuesioner yang tidak kembali dan tidak lengkap untuk diselesaikan, sehingga sampel dalam penelitian ini sebanyak 57 organisasi UMKM.

Variabel yang digunakan dalam penelitian ini meliputi variabel independen yaitu knowledge management yang terdiri dari knowledge implementing, knowledge creating, dan knowledge sharing. Variabel dependen adalah kinerja UMKM dan variabel moderasi adalah kompetensi.

Knowledge implementing menggunakan beberapa indikator, termasuk: patent, licenses technology, knowledge based customer service, knowledge product and embedded technology, separate application product dan knowledge workers at all level. Pertanyaan berisi 5 item pertanyaan dan pertanyaan menggunakan likert skala 1 sampai 5 . Knowledge creation menggunakan beberapa indikator, termasuk: socialization, externalization, combination, dan internalization. Pertanyaan berisi 4 item pertanyaan dan pertanyaan menggunakan likert skala 1 sampai 5. Knowledge sharing menggunakan beberapa indikator, termasuk: comparation, consequences, connections dan conversations. Pertanyaan berisi 4 item pertanyaan dan pertanyaan menggunakan likert skala 1 sampai 5.

Kompetensi menggunakan beberapa indikator termasuk dorongan individu, berpikir strategis, ketegasan dalam mengambil keputusan, penilaian secara komersial, hubungan antar pribadi, kemampuan berkomunikasi, kemampuan untuk beradaptasi dan mengatasi perubahan dan tekanan, kemampuan merencanakan, dan mengendalikan proyek. Pertanyaan berisi 8 item pertanyaan dan pertanyaan menggunakan likert skala 1 sampai 5. Kinerja UMKM menggunakan beberapa indikator, financial perspective, internal perspective, customer perspective dan innovation, and learning perspective. Pertanyaan berisi 4 item pertanyaan dan pertanyaan menggunakan Likert skala 1 sampai 5.

Analisis data untuk mengetahui seberapa besar pengaruh antar variabel menggunakan analisis regresi linier berganda, uji F, Uji t dan uji MRA yang sebelumnya data di analisis reliabilitas dan analisis validitas untuk mengukur kelayakan data melalui aplikasi SPSS versi 20.0

\section{HASIL PENELITIAN DAN PEMBAHASAN}

\section{Uji Reliabilitas}

Analisis uji reliabilitas untuk mengetahui bahwa data yang dianalisis itu reliabel. Dari hasil analisis didapatkan bahwa variabel knowledge management yang terdiri dari knowledge 
creation, knowledge sharing dan knowledge implementing dan peningkatan kinerja organisasi memiliki nilai Cronbach Alpha lebih dari 0.60 atau bisa kita simpulkan data reliable.

Tabel 1. Hasil Uji Reliabilitas

Reliability Statistics

\begin{tabular}{|r|c|}
\hline Cronbach's Alpha & N of Items \\
\hline .657 & 5 \\
\hline
\end{tabular}

Sumber : Data diolah

\section{Uji Validitas}

Analisis uji validitas untuk mengetahui bahwa data yang dianalisis itu valid. Pengukuran data menggunakan SPSS versi 20.0 mendapatkan nilai $\mathrm{r}$ hitung lebih dari 0.30 atau lebih besar dari $\mathrm{r}$ tabel. Dapat disimpulkan bahwa data merupakan data valid dan layak digunakan.

Tabel 2. Uji Validitas

Correlations

\begin{tabular}{|c|c|c|c|c|c|c|}
\hline & & $\begin{array}{c}\text { Knowladge } \\
\text { Implementation }\end{array}$ & $\begin{array}{c}\text { Knowledge } \\
\text { Creation }\end{array}$ & $\begin{array}{c}\text { Knowladge } \\
\text { Sharing } \\
\end{array}$ & $\begin{array}{l}\text { Kinerja } \\
\text { UMKM }\end{array}$ & Kompetensi \\
\hline \multirow{3}{*}{$\begin{array}{l}\text { Knowledge } \\
\text { implementation }\end{array}$} & $\begin{array}{l}\text { Pearson } \\
\text { Correlation }\end{array}$ & 1 & .154 & .038 & $.573^{* *}$ & $.293^{*}$ \\
\hline & Sig. (2-tailed) & & .254 & .778 & .000 & .027 \\
\hline & $\mathrm{N}$ & 57 & 57 & 57 & 57 & 57 \\
\hline \multirow{3}{*}{$\begin{array}{l}\text { Knowledge } \\
\text { Creation }\end{array}$} & $\begin{array}{l}\text { Pearson } \\
\text { Correlation }\end{array}$ & .154 & 1 & .240 & $.630^{* *}$ & .005 \\
\hline & Sig. (2-tailed) & .254 & & .072 & .000 & .969 \\
\hline & $\mathrm{N}$ & 57 & 57 & 57 & 57 & 57 \\
\hline \multirow{3}{*}{$\begin{array}{l}\text { Knowledge } \\
\text { Sharing }\end{array}$} & $\begin{array}{l}\text { Pearson } \\
\text { Correlation }\end{array}$ & .038. & .240 & 1 & $.512^{* *}$ & $.384^{* *}$ \\
\hline & Sig. (2-tailed) & .778 & .072 & & .000 & .003 \\
\hline & $\mathrm{N}$ & 57 & 57 & 57 & 57 & 57 \\
\hline \multirow{3}{*}{$\begin{array}{l}\text { Kinerja } \\
\text { UMKM }\end{array}$} & $\begin{array}{l}\text { Pearson } \\
\text { Correlation }\end{array}$ & $.573^{* *}$ & $.630^{* *}$ & $.512^{* *}$ & 1 & $.432^{* *}$ \\
\hline & Sig. (2-tailed) & .000 & .000 & .000 & & .001 \\
\hline & $\mathrm{N}$ & 57 & 57 & 57 & 57 & 57 \\
\hline \multirow{3}{*}{ Kompetensi } & $\begin{array}{l}\text { Pearson } \\
\text { Correlation }\end{array}$ & $.293^{*}$ & .005 & $.384^{* *}$ & $.432^{* *}$ & 1 \\
\hline & Sig. (2-tailed) & .027 & .969 & .003 & .001 & \\
\hline & $\mathrm{N}$ & 57 & 57 & 57 & 57 & 57 \\
\hline
\end{tabular}

**. Correlation is significant at the 0.01 level (2-tailed).

*. Correlation is significant at the 0.05 level (2-tailed).

Sumber: Data diolah 


\section{Regresi Linier Berganda}

Tabel 3. Hasil Analisis Linier Berganda

Coefficients $^{\mathrm{a}}$

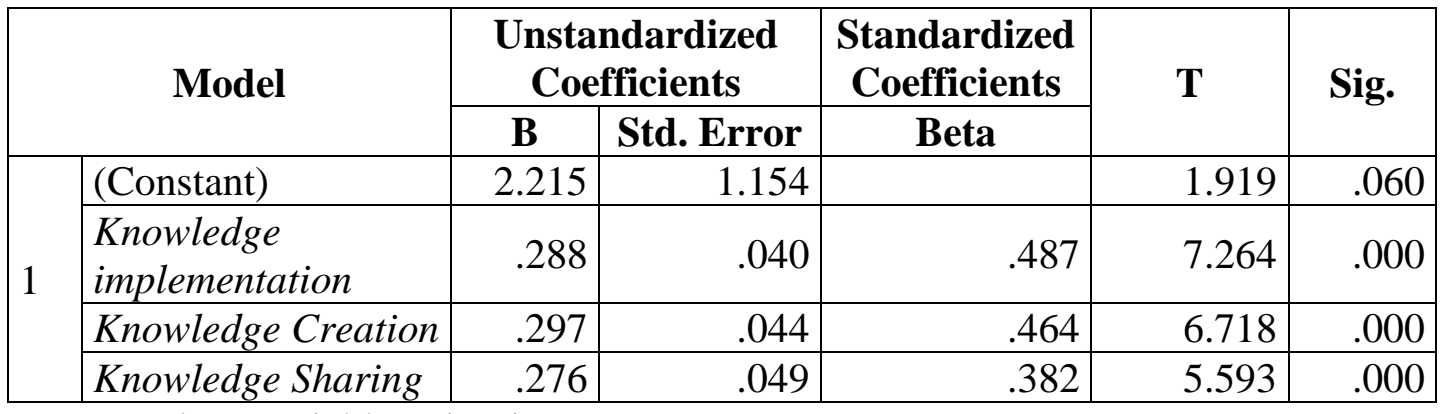

a. Dependent Variable: Kinerja UMKM

Sumber : Data primer diolah, 2020

Berdasarkan hasil uji dengan menggunakan SPSS versi 20.0 diperoleh hasil persamaan regresi linier berganda adalah sebagai berikut:

Kinerja $\mathrm{UMKM}=2.215+0,288 \mathrm{X}_{1}+0,297 \mathrm{X}_{2}+0,276 \mathrm{X}_{3}$

$$
\begin{aligned}
& \mathrm{X}_{1}=\text { knowledge implementation } \\
& \mathrm{X}_{2}=\text { knowledge creation } \\
& \mathrm{X}_{3}=\text { knowledge sharing }
\end{aligned}
$$

Koefisien regresi atas knowledge implementation adalah 0,288, variabel knowledge creation adalah 0,297 dan variabel knowledge sharing sebesar 0,276 sedangkan nilai konstan sebesar 2.215 .

\section{Uji t}

Berdasarkan tabel 3 tersebut di atas, nilai t hitung atas knowledge implementasi sebesar 7.264 dan nilai t tabel sebesar 2.00488. Jadi t hitung > t tabel dapat disimpulkan bahwa variabel knowledge implementasi berpengaruh positif secara signifikan terhadap peningkatan kinerja UMKM secara parsial maka $\mathrm{H}_{1}$ diterima.

Nilai t hitung atas knowledge creation sebesar 6.718 dan nilai t tabel sebesar 2.00488 . Jadi t hitung > t tabel dapat disimpulkan bahwa variable knowledge creation berpengaruh positif secara signifikan terhadap peningkatan kinerja UMKM secara parsial maka $\mathrm{H}_{2}$ diterima.

Nilai t hitung atas knowledge sharing sebesar 5.593 dan nilai t tabel sebesar 2.00488. Jadi t hitung > t tabel dapat disimpulkan bahwa variable knowledge sharing berpengaruh positif secara signifikan terhadap peningkatan kinerja UMKM secara parsial maka $\mathrm{H}_{3}$ 
diterima.

Uji F

Tabel 4. Hasil Uji F hitung

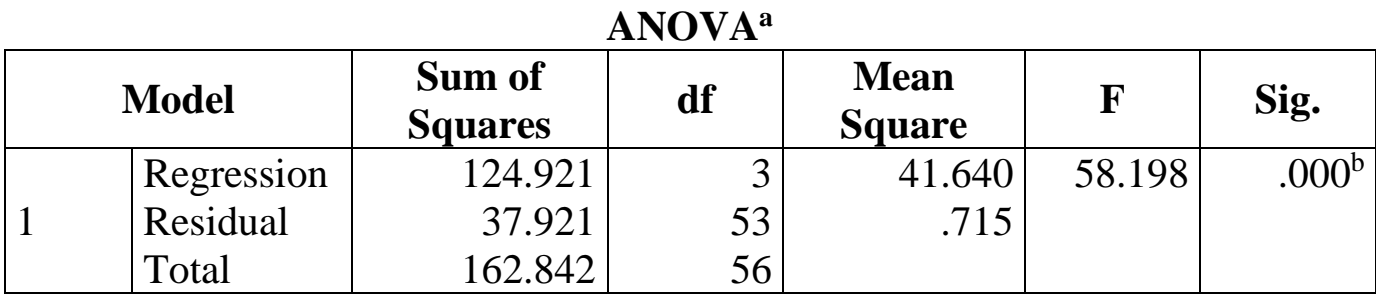

a. Dependent Variable: Kinerja UMKM

b. Predictors: (Constant), Knowledge Sharing, Knowledge Implementasi,

Knowledge Creation

Sumber : Pengelolaan data dengan SPSS 20.0

Berdasarkan tabel 4 tersebut di atas, nilai $\mathrm{F}$ hitung sebesar 58.198 dan nilai $\mathrm{F}$ tabel sebesar 2.78 jadi $\mathrm{F}$ hitung > F tabel dapat disimpulkan bahwa variable knowledge implementasi, knowledge creation dan knowledge sharing berpengaruh positif secara signifikan terhadap peningkatan kinerja UMKM secara simultan maka $\mathrm{H}_{5}$ diterima.

Tabel 5. Hasil Uji Determinasi Variabel Independen Terhadap Variabel Dependen

Model Summary

\begin{tabular}{|l|r|r|r|rr|}
\hline Model & \multicolumn{1}{|c|}{ R } & \multicolumn{1}{|c|}{ R Square } & Adjusted R Square & \multicolumn{2}{|c|}{$\begin{array}{c}\text { Std. Error of the } \\
\text { Estimate }\end{array}$} \\
\hline 1 & $.876^{\mathrm{a}}$ & .767 & .754 & .846 \\
\hline
\end{tabular}

a. Predictors: (Constant), Knowledge Sharing, Knowledge Implementasi, Knowledge Creation

Sumber: Hasil Output SPSS 20, data diolah peneliti (2020)

Berdasarkan tabel 5, Adjusted $R$ Square menunjukkan 0,754 atau 75,4\% > Hal ini berarti kemampuan seluruh variabel bebas yakni knowledge management terhadap kinerja UMKM sebesar 75,4\%. Sisanya sebesar $24,6 \%$ dijelaskan oleh variabel lain di luar penelitian.

\section{Uji Moderated Regression Analysis (MRA)}

Dari tabel 6 diketahui bahwa kompetensi tidak mampu memoderasi hubungan antara variabel knowledge implementing terhadap kinerja UMKM. Dapat dilihat dari nilai signifikansi yang lebih besar dari $\alpha(0.257>0,05)$. 
Tabel 6. Uji MRA Pengaruh kompetensi dalam memoderasi hubungan antara variabel knowledge implementing terhadap kinerja UMKM

Coefficients $^{\mathrm{a}}$

\begin{tabular}{|c|c|c|c|c|c|}
\hline \multirow[t]{2}{*}{ Model } & \multicolumn{2}{|c|}{$\begin{array}{c}\text { Unstandardized } \\
\text { Coefficients }\end{array}$} & \multirow{2}{*}{$\begin{array}{c}\text { Standardized } \\
\text { Coefficients } \\
\text { Beta } \\
\end{array}$} & \multirow[t]{2}{*}{$\mathbf{t}$} & \multirow[t]{2}{*}{ Sig. } \\
\hline & B & Std. Error & & & \\
\hline (Constant) & 8.175 & 5.158 & & 1.585 & .119 \\
\hline $\begin{array}{l}\text { Knowledge } \\
\text { implementation }\end{array}$ & -.246 & .254 & -.417 & -.969 & .337 \\
\hline Kompetensi & .449 & .321 & .449 & 1.397 & .168 \\
\hline KI*Kompetensi & .017 & .015 & .760 & 1.146 & .257 \\
\hline
\end{tabular}

a. Dependent Variable: Kinerja UMKM

Sumber: Hasil Output SPSS 20, data diolah peneliti (2020)

Dari tabel 7 diketahui bahwa kompetensi tidak mampu memoderasi hubungan antara variabel knowledge implementing terhadap kinerja UMKM. Dapat dilihat dari nilai signifikansi yang lebih besar dari $\alpha(0.878>0,05)$. Namun, kompetensi berhubungan dengan variabel dependen yaitu kinerja UMKM. Hal ini ditunjukkan dengan nilai signifikansi yang lebih kecil dari $\alpha(0.014<0,05)$. Maka dalam hal ini, kompetensi bukanlah variabel moderasi, melainkan variabel prediktor.

Tabel 7. Uji MRA Pengaruh kompetensi dalam memoderasi hubungan antara variabel knowledge creating terhadap kinerja UMKM

Coefficients $^{\mathbf{a}}$

\begin{tabular}{|c|c|c|c|c|c|}
\hline \multirow[t]{2}{*}{ Model } & \multicolumn{2}{|c|}{$\begin{array}{c}\text { Unstandardized } \\
\text { Coefficients }\end{array}$} & \multirow{2}{*}{$\begin{array}{c}\text { Standardized } \\
\text { Coefficients } \\
\text { Beta }\end{array}$} & \multirow[t]{2}{*}{$\mathbf{t}$} & \multirow[t]{2}{*}{ Sig. } \\
\hline & B & Std. Error & & & \\
\hline (Constant) & 1.868 & 5.633 & & .332 & .741 \\
\hline $\begin{array}{l}\text { Knowledge } \\
\text { Creation }\end{array}$ & .111 & .381 & .173 & .291 & .772 \\
\hline Kompetensi & .832 & .328 & .833 & 2.535 & .014 \\
\hline KC*Kompetensi & -.003 & .021 & -.130 & -.155 & .878 \\
\hline
\end{tabular}

a. Dependent Variable: Kinerja UMKM

Sumber: Hasil Output SPSS 20, data diolah peneliti (2020)

Dari tabel 8 diketahui bahwa kompetensi tidak mampu memoderasi hubungan antara variabel knowledge sharing terhadap kinerja UMKM. Dapat dilihat dari nilai signifikansi yang lebih besar dari $\alpha(0.489>0,05)$. 
Tabel 8. Uji MRA Pengaruh kompetensi dalam memoderasi hubungan antara variabel knowledge sharing terhadap kinerja UMKM

Coefficients $^{\mathrm{a}}$

\begin{tabular}{|l|r|r|r|r|r|}
\hline \multirow{2}{*}{ Model } & \multicolumn{2}{|c|}{$\begin{array}{c}\text { Unstandardized } \\
\text { Coefficients }\end{array}$} & $\begin{array}{l}\text { Standardized } \\
\text { Coefficients } \\
\text { Beta }\end{array}$ & t & \multirow{2}{*}{ Sig. } \\
\cline { 2 - 6 } & \multicolumn{1}{|c|}{ B } & Std. Error & & \\
\hline (Constant) & 6.840 & 6.331 & & 1.080 & .285 \\
\hline $\begin{array}{l}\text { Knowledge } \\
\text { Sharing }\end{array}$ & -.274 & .405 & -.379 & -.675 & .503 \\
\hline Kompetensi & .594 & .361 & .594 & 1.644 & .106 \\
\hline KS*Kompetensi & .016 & .022 & .569 & .697 & .489 \\
\hline
\end{tabular}

a. Dependent Variable: Kinerja UMKM

Sumber: Hasil Output SPSS 20, data diolah peneliti (2020)

\section{Pembahasan}

Berdasarkan hasil uji dengan menggunakan SPSS versi 20.0 diperoleh hasil persamaan regresi linier berganda adalah sebagai berikut:

Kinerja UMKM $=2.215+0,288 \mathrm{X}_{1}+0,297 \mathrm{X}_{2}+0,276 \mathrm{X}_{3}$

$$
\begin{aligned}
& \mathrm{X}_{1}=\text { knowledge implementation } \\
& \mathrm{X}_{2}=\text { knowledge creation } \\
& \mathrm{X}_{3}=\text { knowledge sharing }
\end{aligned}
$$

Koefisien regresi atas knowledge implementation adalah 0,288 variabel knowledge creation adalah 0,297 dan variabel knowledge sharing sebesar 0,276 sedangkan nilai konstan sebesar 2.215.

Knowledge implementing secara parsial memiliki pengaruh positif dan signifikan terhadap kinerja UMKM. Hal ini membuktikan bahwa penerapan pengetahuan dalam pengelolaan organisasi merupakan hal yang bisa memberikan pertumbuhan kinerja organisasi. Organisasi dapat terus berkembang bersamaan dengan pengetahuan implementasi yang diterapkan dan terus ditingkatkan melalui pelatihan, workshop dan seminar dan kegiatan-kegiatan untuk meningkatkan pengetahuan. Penelitian ini sesuai dengan teori Maier (2007) menyatakan bahwa knowledge management mempengaruhi kinerja organisasi melalui kerangka strategi dan mendesain organisasi menjadi lebih berdaya saing.

Knowledge creating mempunyai pengaruh positif dan signifikan terhadap peningkatan kinerja UMKM. Hal ini membuktikan bahwa knowledge creating merupakan pengetahuan yang dapat memberikan pertumbuhan kinerja organisasi. Organisasi dapat terus berkembang 
bersamaan dengan peningkatan knowledge creating. Menurut Nonaka, (1995) pada bagian ini dikembangkan suatu kerangka dasar pengetahuan yang diintegrasikan ke dalam teori knowledge creation dalam organisasi, kerangka dasar tersebut terdiri dari dua dimensi, yaitu epistemologi dan ontology.

Knowledge sharing mempunyai pengaruh positif dan signifikan terhadap peningkatan kinerja UMKM. Hal ini membuktikan bahwa knowledge sharing merupakan pengetahuan yang dapat memberikan pertumbuhan kinerja organisasi. Organisasi dapat terus berkembang bersamaan dengan peningkatan knowledge Sharing. Menurut Gagné (2009) knowledge sharing, adalah tahapan diseminasi dan penyediaan pengetahuan pada saat yang tepat untuk karyawan yang membutuhkan.

Knowledge management yang terdiri dari knowledge implementing, knowledge creating dan knowledge sharing secara simultan berpengaruh signifikan terhadap peningkatan kinerja UMKM. Penelitian ini sesuai dengan penelitian yang dilakukan oleh Saraswati \& Widiartanto (2016) pada industri kreatif di kota semarang menyatakan bahwa bahwa adanya adanya pengaruh knowledge management terhadap kinerja organisasi. Kinerja UMKM terus berkembang seiring dengan peningkatan knowledge management. Hal yang dibutuhkan untuk perkembangan menjadi UMKM yang memiliki daya kompetitif dan menjadi UMKM unggul.

Uji Moderated Regression Analysis (MRA) dilakukan untuk menguji hipotesis kelima $\left(\mathrm{H}_{5}\right)$ yang bertujuan untuk menguji apakah kompetensi memoderasi knowledge management yang terdiri dari knowledge implementing, knowledge creation dan knowledge sharing yang signifikan terhadap kinerja UMKM.

Pada tabel 6 dapat dijelaskan bahwa hasil analisis dengan menggunakan uji Moderated Regression Analysis (MRA) mendapatkan hasil bahwa knowledge implementing tidak mampu memoderasi terhadap kinerja UMKM. Hal ini dibuktikan dari nilai signifikansi interaksi knowledge implementing lebih besar dari $\alpha$ yaitu 0,257>0,05. Hal ini menunjukkan bahwa Ho diterima yang artinya kompetensi tidak mampu memoderasi pengaruh knowledge implementing terhadap kinerja UMKM. Kompetensi tidak mampu memoderasi knowledge implementing dikarenakan untuk UMKM belum menerapkan standar kompetensi sehingga seiring berjalannya usaha kompetensi belum dibutuhkan UMKM sehingga tidak bisa memoderasi antara knowledge implementing dengan kinerja UMKM.

Pada tabel 7 dapat dijelaskan bahwa hasil analisis dengan menggunakan uji Moderated Regression Analysis (MRA) mendapatkan hasil bahwa knowledge creation tidak mampu 
memoderasi terhadap kinerja UMKM. Hal ini dibuktikan dari nilai signifikansi interaksi knowledge creation lebih besar dari $\alpha$ yaitu $0,878>0,05$. Hal ini menunjukkan bahwa Ho diterima yang artinya kompetensi tidak mampu memoderasi pengaruh knowledge creation terhadap kinerja UMKM. Kompetensi tidak mampu memoderasi knowledge creation dikarenakan untuk UMKM belum menerapkan standar kompetensi sehingga seiring berjalannya usaha kompetensi belum dibutuhkan UMKM sehingga tidak bisa memoderasi antara knowledge creation dengan kinerja UMKM.

Pada tabel 8 dapat dijelaskan bahwa hasil analisis dengan menggunakan uji Moderated Regression Analysis (MRA) mendapatkan hasil bahwa knowledge sharing tidak mampu memoderasi kinerja UMKM. Hal ini dibuktikan dari nilai signifikansi interaksi knowledge sharing lebih besar dari $\alpha$ yaitu $0,489>0,05$. Hal ini menunjukkan bahwa Ho diterima yang artinya kompetensi tidak mampu memoderasi pengaruh knowledge sharing terhadap kinerja UMKM. Kompetensi tidak mampu memoderasi knowledge sharing dikarenakan untuk UMKM belum menerapkan standar kompetensi sehingga seiring berjalannya usaha kompetensi belum dibutuhkan UMKM sehingga tidak bisa memoderasi antara knowledge sharing dengan kinerja UMKM.

\section{E. KESIMPULAN}

Berdasarkan hasil analisis penelitian yang telah dilakukan maka dapat diambil kesimpulan bahwa secara parsial knowledge implementing berpengaruh signifikan positif terhadap peningkatan kinerja UMKM di kabupaten Pemalang. Variabel knowledge implementing memiliki pengaruh sebesar 0.288 atau $28.8 \%$. Secara parsial knowledge creating berpengaruh signifikan positif terhadap peningkatan kinerja UMKM dan pengaruhnya sebesar 0.297 atau 29.7\%. Variabel knowledge creating memiliki pengaruh paling besar diantara variabel yang lain dalam penelitian ini. Secara parsial knowledge sharing berpengaruh signifikan positif terhadap peningkatan kinerja UMKM, pengaruhnya sebesar 0.276 atau 27.6\%. Secara bersama sama atau simultan knowledge implementing, knowledge creating, dan knowledge sharing berpengaruh signifikan positif terhadap peningkatan kinerja UMKM. Kompetensi tidak mampu memoderasi hubungan antara knowledge implementing, knowledge creating, dan knowledge sharing terhadap kinerja UMKM. 


\section{Saran}

Bagi calon pemilik UMKM harusnya sebelum memutuskan untuk menjalankan usaha dalam skala mikro kecil dan menengah untuk dapat mempelajari atau memiliki pengetahuan manajemen diantaranya adalah knowledge implementing, knowledge creating, dan knowledge sharing. Begitu juga untuk pemilik UMKM yang sudah berjalan upaya untuk meningkatkan kinerja UMKMnya salah satu cara yang dapat dilakukan adalah peningkatan knowledge management. Saran untuk penelitian selanjutnya adalah karena keterbatasan penelitian ini lingkup objek penelitian sempit maka penelitian selanjutnya dapat mencari objek penelitian yang luas dan dapat menambahkan variable-variabel lain dan menggunakan variabel intervensi yang dapat mempengaruhi kinerja UMKM.

\section{DAFTAR PUSTAKA}

Armstrong, M. (1994) Manajemen Sumber Daya Manusia: A Handbook Of. Human Resource Management. PT Elex Mediakomputindo. Jakarta.

Bank Indonesia dan LPPI. (2015). Profil Bisnis Usaha Mikro, Kecil dan Menengah (UMKM). In Bank Indonesia dan LPPI.

Humaira, I., \& Sagoro, E. M. (2018). Pengaruh Pengetahuan Keuangan, Sikap Keuangan, dan Kepribadian Terhadap Perilaku Manajemen Keuangan Pada Pelaku UMKM Sentra Kerajinan Batik Kabupaten Bantul. Jurnal Nominal, 7(1), 96-108.

https://ekonomi.bisnis.com/read/20200722/9/1269901/dampak-covid-19-ke-ukm-16-persenpelaku-usaha-pangkas-karyawan (diakses 31 Agustus 2020)

https://money.kompas.com/read/2020/08/05/120854826/pertumbuhan-ekonomi-ri-minus532-persen-pada-kuartal-ii-2020\#: :text=JAKARTA\%2C\%20KOMPAS.com\%20\%20Badan,kumulatif\%20terkontraksi\%201\%2C26\%20persen (diakses 31 Agustus 2020)

https://ekonomi.kompas.com/read/2018/07/10/200246326/umkm-mampu-dongkrakpertumbuhan-ekonomi. Diakses 01 Januari 2020

http://dinkop-umkm.jatengprov.go.id/resc/img/media/3520data_series_umkm_tw_i_2019_upload.xlsx . diakses 3 Desember 2019

Inkinen, H., Kianto, A. and Vanhala, M. (2015). Knowledge Management Practices and Innovation Performance in Finland. Baltic Journal of Management, 10(4), 432-455. DOI: 10.1108/BJM-10-2014-0178

Islami, A. C., Kunaifi, A., \& Gunawan, J. (2017). Ragam Pengukuran Kinerja pada Usaha Mikro, Kecil, dan Menengah (UMKM) di Surabaya. Jurnal Sains Dan Seni ITS, 6(2), 168-171. https://doi.org/10.12962/j23373520.v6i2.23112

Maier, R. (2007). In Knowledge Management Systems: Information and Communication 
Technologies for Knowledge Management. Spriger. https://doi.org/10.1007/978-3-54071408-8

OECD/Statistics Canada. (2004). Measuring Knowledge Management in the Business

Sector: First Steps, Knowledge management. OECD Publishing:

Paris. https://doi.org/10.1787/9789264100282-en

Monsow, E.Y., Runtuwene, M.R., \& Rumawas, W. (2017). Pengaruh Knowledge

Management terhadap kinerja karyawan di Bank Mayapada KCU Mega Mas Manado.

Jurnal Administrasi Bisnis, 6(1), 1-10

Nonaka, I. (1994). A Dynamic Theory of Organizational Knowledge Creation. Organization Science, 5(1), 14-37 https://doi.org/10.1287/orsc.5.1.14

Nonaka, I., \& Takeuchi, H. (1995). The knowledge-creating company: How Japanese companies create the dynamics of innovation. New York: Oxford University Press.

Saraswati, A., \& Widiartanto, W. (2016). Pengaruh Implementasi Knowledge Management Terhadap Kinerja Organisasi Melalui Inovasi Sebagai Variabel Intervening (Studi Kasus Pada UMKM Industri Kreatif Digital di Kota Semarang). Jurnal Ilmu Administrasi Bisnis, 5(4), 359-373.

Gagné, M. (2009). A model of knowledge-sharing motivation. Human Resource Management., 48, 571-589. doi:10.1002/hrm.20298

Sudiarta, I. P. L. E., Kirya, I. K., dan Cipta, W. (2014). Analisis Faktor-Faktor Yang Mempengaruhi Kinerja Usaha Mikro Kecil dan Menengah (UMKM) Di Kabupaten Bangli. Jurnal Jurusan Manajemen, 2(1)

Undang-Undang Nomor 20 Tahun 2008 Tentang Usaha Mikro, Kecil, Dan Menengah

Wachyu, W., \& Winarto, A. (2020). Peran Fintech dalam Usaha Mikro Kecil dan Menengah (UMKM). Jurnal Ekonomi Dan Ekonomi Syariah (JESYA), 3(1), 61-73. https://doi.org/https://doi.org/10.36778/jesya.v3i1.132

Wahyudi, B. (2002), Manajemen Sumber Daya Manusia. Jakarta : Sulita 